\title{
The relevance of pedigrees in the conservation genomics era.
}

\author{
Stephanie Galla ${ }^{1}$, Liz Brown ${ }^{2}$, Yvette Couch-Lewis ${ }^{3}$, Ilina Cubrinovska ${ }^{4}$, Daryl Eason ${ }^{2}$, \\ Rebecca Gooley ${ }^{5}$, Jill Hamilton ${ }^{6}$, Julie Heath ${ }^{1}$, Samantha Hauser ${ }^{7}$, Emily Latch ${ }^{8}$, Marjorie \\ Matocq $^{9}$, Anne Richardson ${ }^{10}$, Jana Wold ${ }^{4}$, Carolyn J. Hogg ${ }^{11}$, Anna Santure ${ }^{12}$, and Tammy \\ Steeves $^{4}$ \\ ${ }^{1}$ Boise State University \\ ${ }^{2}$ New Zealand Department of Conservation \\ ${ }^{3}$ Te Rūnanga o Ngāi Tahu, Te Whare o Te Waipounamu \\ ${ }^{4}$ University of Canterbury \\ ${ }^{5}$ Smithsonian-Mason School of Conservation \\ ${ }^{6}$ North Dakota State University \\ ${ }^{7}$ University of Wisconsin-Milwaukee \\ ${ }^{8}$ University of Wisconsin - Milwaukee \\ ${ }^{9}$ University of Nevada Reno \\ ${ }^{10}$ The Isaac Conservation and Wildlife Trust \\ ${ }^{11}$ University of Sydney \\ ${ }^{12}$ The University of Auckland
}

September 13, 2021

\begin{abstract}
Over the past 50 years conservation genetics has developed a substantive toolbox to inform species management. One of the most long-standing tools available to manage genetics - the pedigree - has been widely used to characterize diversity and maximize evolutionary potential in threatened populations. Now, with the ability to use high throughput sequencing (HTS) to estimate relatedness, inbreeding, and genome-wide functional diversity, some have asked whether it is warranted for conservation biologists to continue collecting and collating pedigrees for species management. In this perspective, we argue that pedigrees remain a relevant tool, and when combined with genomic data, create an invaluable resource for conservation genomic management. Genomic data can address pedigree pitfalls (e.g., founder relatedness, missing data, uncertainty), and in return robust pedigrees allow for more nuanced research design, including well-informed sampling strategies and quantitative analyses (e.g., heritability, linkage) to better inform genomic inquiry. We further contend that building and maintaining pedigrees provides an opportunity to strengthen trusted relationships among conservation researchers, practitioners, Indigenous Peoples, and local communities.
\end{abstract}

Keywords: conservation genomics, quantitative genetics, pedigree, kinship, ex situ, in situ

\section{Introduction}

The conservation genetics toolbox

Since the late 1960's, conservation genetics has grown from a handful of techniques into a fully-fledged discipline that uses genetic information to inform the conservation management of threatened species worldwide (Avise 2008). This field has developed a substantive toolbox applied to understand phylogenetics and species delimitation (e.g., Yusefi et al., 2020; Coimbra et al., 2021), population structure and demographics (e.g., Coimbra et al., 2020), natural community profiling (e.g., Young et al., 2020), and the level of standing genetic variation within and among populations (e.g., Zhang, Luan, Ren, Hu, \& Yin, 2020). 
Much discussion regarding the conservation genetic toolbox has been dedicated to the types of variants that are used for genetic inference, and for good reason: in a relatively short time frame, the field has experienced remarkable growth, from detecting variants using allozyme protein electrophoresis to detecting hundreds of thousands of variants through high throughput sequencing (HTS) approaches (Hohenlohe, Funk, \& Rajora, 2021). While the field of conservation genetics was founded on managing putatively neutral diversity as a proxy for evolutionary potential (Yoder, Poelstra, Tiley, \& Williams, 2018), new HTS sequencing and computational tools make it possible for researchers to elucidate the genomic basis of functional traits important to adaptation, which has implications to understanding how species may respond to a changing world (Hoelzel, Bruford, \& Fleischer, 2019; Mable, 2019).

As HTS continues to advance, there will no doubt be more new and exciting tools incorporated into conservation genetic inquiry. In addition to new methods enabled by advances in HTS, there remains one long-standing tool within the conservation genetics toolbox that is often overlooked: the pedigree. Pedigrees, or documented ancestry of individuals in a population, have been recorded by humans for millennia. These family trees have long provided a proxy for understanding the transmission of traits from generation to generation, and maintain diverse applications in agriculture (e.g., Smith, Duvick, Smith, Cooper, \& Feng, 2004), human health (Bennett, 2011), evolutionary biology (Kruuk \& Hill, 2008), and conservation (e.g., Ballou et al., 2010). Sewall Wright famously advanced the utility of pedigrees through his contributions towards pedigree-based path analysis, inbreeding, and kinship estimates (Wright, 1922; Ballou, 1983). Assuming Mendelian inheritance, pedigrees provide an estimate of kinship as the probability of alleles being identical-by-descent (IBD) from a common ancestor (Lacy, 1995). As the fields of conservation biology and genetics emerged in the second half of the 20th century, these same principles were used to estimate kinship, inbreeding, and heritability of functional traits in threatened populations in an effort to conserve evolutionary potential.

\section{Pedigrees in conservation management}

Pedigrees have been particularly well suited for the genetic management of captive (ex situ) or intensively managed wild (in situ) or semi-wild ('sorta' situ; Wildt et al., 2019) populations of animals and plants, where ancestry is more reliably documented. Pedigree use is exemplified by the zoo and aquarium community, who have built a data-driven paradigm of pedigree-based management, including user-friendly software to manage pedigree information (e.g., SPARKS, PopLink, ZIMS; Faust et al., 2019, Species 360 2021) and to calculate pedigree-based genetic statistics (e.g., PMx, Lacy, Ballou, \& Pollak, 2012). Given these readily available tools, and the relative ease and low cost of maintaining parentage information for many species being intensively managed, pedigrees offer an achievable means of managing genetic diversity in these populations. Pedigree-based conservation management is often kinship-based, with the coefficient of kinship $(f)$ being a metric of the coefficient of relatedness $(R, R=2 f$ in the absence of inbreeding; Lacy, 2005, 2009). Common pedigree-based statistics for small population management include mean kinship (i.e., MK, or the average kinship of one individual to all others in a population, including itself), inbreeding coefficients $(F)$, founder genome-equivalents (i.e., the effective number of individuals founding a population), and population-level gene diversity (GD, also known as expected heterozygosity; Lacy, 1995; Ballou et al., 2010). These statistics are frequently used to track loss of founder alleles over time (e.g., MacCluer, VandeBerg, Read, \& Ryder, 1989) and minimize mean kinship and inbreeding in threatened populations to maintain the evolutionary potential of the species of interest (Ivy, Miller, Lacy, \& DeWoody, 2009; Willougby et al., 2015; Galla et al., 2020; Fig. 1). Indeed, studies have shown the efficacy of this approach (Lacy, 2009), with pedigrees being used to measure and manage diversity and inbreeding in animals worldwide, including Atlantic and sockeye salmon (Salmo salar and Oncorhynchus nerka, respectively; O'Reilly \& Kozfkay, 2014), Tasmanian devil (Sarcophilus harrisii; McLennan et al., 2018; Wright, Hogg, McLennan, Belov, \& Grueber, 2021), American bison (Bison bison; Giglio, Ivy, Jones, \& Latch, 2016, 2018), whooping crane (Grus americana; Boardman, Mace, Peregoy, \& Ivy, 2017), takahē (Porphyrio hochstetteri; Grueber \& Jamieson, 2008), and Houbara bustard (Chlamydotis undulata undulata; Rabier, Robert, Lacroix, \& Lesobre, 2020). When pedigrees are complete and accurate, they have been shown to explain more variation in inbreeding than microsatellites do (Nietlisbach et al., 2017) and provide similar estimates of relatedness 
to thousands to tens of thousands of genome-wide single nucleotide polymorphisms (i.e., SNPs; Galla et al., 2020). While pedigrees have been extensively used to manage genome-wide diversity of animals in zoos and aquaria, a recent review by Wood et al., (2020) has highlighted their potential for managing diversity and viability for plant collections and seed banks. Ongoing efforts are being made to optimize collections and maintain plant material ex situ for long-term conservation and potential use in future restoration (Di Santo \& Hamilton, 2020). The goals of these collections are to both preserve diversity representative of in situ population differences across a species' range, and to ensure that ex situ population genetic variation is maintained to preserve adaptive evolutionary potential (Di Santo \& Hamilton, 2020; Hamilton et al., 2020). Given the overlapping goals - but differing approaches - of plant and animal conservation breeding programs, we anticipate that zoo, aquaria, and botanical communities will learn much from one another as different approaches are developed and tested.

Most zoos and aquaria use pedigrees in a well-supported paradigm of measuring and managing putatively neutral genome-wide diversity, but pedigrees have also been used to characterize and manage functional diversity within ex situ plant and fisheries systems. For example, in 1983 the American Chestnut Foundation embarked on an ambitious breeding program to backcross blight-susceptible American chestnut (Castanea dentata) - a species on the brink of extinction - with blight-resistant Chinese chestnut ( C. mollisima). In this instance, ancestry data from pedigrees and phenotypic data on blight resistance were used for crossing programs, based on the hypothesis that blight resistance had a genetic basis (Westbrook et al., 2020). In addition to disease resistance, pedigrees are often used in greenhouses or intensively managed common gardens to understand the functional ability of plants to cope with stress through gene-by-environment (i.e., GxE) experiments (e.g., George et al., 2020). These experiments aim to disentangle genetic (as derived from pedigree-based kinship) and environmental contributions, and their interactions, to explain phenotypes of interest in individuals. Conservation biologists can then use predictions of local environmental conditions in the short- to medium-term to select well-adapted individuals or varieties for conservation translocations and restoration (e.g., Richardson \& Chaney, 2018).

Pedigree data has also advanced our understanding of wild populations and ability to manage them (i.e., in situ or sorta situ conservation; Kruuk \& Hill, 2008; Wildt et al., 2019). For a pedigreed natural population of Florida scrub jays (Aphelocoma coerulescens), researchers used pedigrees to predict the effects of selection and gene flow on how declining populations might evolve in a short time period (Chen et al., 2019). A wild pedigree for gray wolves (Canus lupus) in Yellowstone National Park combined with phenotypes recorded for those individuals led to advances in understanding the heritability of behaviour and the genetic basis of mange in this iconic species (vonHoldt et al., 2020; DeCandia, Schrom, Brandell, Stahler, \& von Holdt, 2021). Pedigrees have also been used in Eastern Massasauga rattlesnakes (Sistrurus catenatus) to elucidate dispersal and connectivity between populations, with implications for restoration and translocation efforts (Martin et al., 2021). Important to conservation efforts for small and isolated wild populations is the ability to re-establish gene flow using conservation translocations (i.e., genetic rescue; Ralls, Sunnucks, Lacy, \& Frankham, 2020). Documented ancestry of wild populations can help refine estimates of effective population size, social group structure, genetic connectivity among populations, and potential local adaptation amongst populations, which can aid in designing successful translocation programs that minimize inbreeding depression while avoiding outbreeding depression. For example, pedigrees have been used to inform genetic conservation or rescue efforts for wild populations of black-tailed prairie dogs (Cynomys ludovicianus; Shier 2006), Rocky Mountain bighorn sheep (Ovis canadensis; Hogg, Forbes, Steele, \& Luikart, 2006), Scandanavian gray wolves (Åkesson et al., 2016), and Tasmanian devils (McLennan, Grueber, Wise, Belov, \& Hogg, 2020). From these examples, pedigrees have continued to provide an invaluable resource for understanding and managing diversity in plants and animals. However, there are pitfalls for pedigrees that can affect their accuracy and utility for conservation efforts.

\section{Pedigree pitfalls and solutions}

One common assumption of pedigrees is that the founding individuals (hereafter, founders) are equally unrelated. As many threatened populations have experienced significant declines before populations are 
pedigreed, founders from these populations may include more variance in kinship amongst one another than individuals randomly sampled from non-threatened populations. For instance, a study of microsatellite-based relatedness in kākāpō (Strigops habroptilus) demonstrated that full-sibling and half-sibling relationships were represented amongst founders (Bergner, Jamieson, \& Robertson, 2014), which has been confirmed with thousands of genome-wide SNPs (New Zealand Department of Conservation, unpublished data). Research in Tasmanian devil has further shown that inferring estimates of relatedness amongst founders using molecular and geographic data revealed significantly higher inbreeding coefficients in the years following establishment, compared to pedigrees that treat founders as equally unrelated (Hogg et al., 2019). While these effects are ameliorated with higher pedigree depth from founding individuals (Balloux et al., 2004), this assumption can be perpetuated when individuals of unknown ancestry (e.g., supplemented individuals, or individuals with missing information) are incorporated into the pedigree in later generations. In addition to these issues, pedigrees are also susceptible to human transcription errors, which can compound in pedigrees over time (Hammerly, de la Cerda, Bailey, \& Johnson, 2016).

Missing information is often a concern for wild pedigrees where parentage is difficult to ascertain. For example, accurate parentage can be challenging due to the time and cost required to monitor breeding individuals in the wild, coupled with the dispersal potential and breeding behaviour of the organism (e.g., polygamous species like flock breeding birds, herd-breeding mammals, and open-pollinated plants; Ashley, 2010; Ivy, Putnam, Navarro, Gurr, \& Ryder, 2016; Wildt et al., 2019). This challenge is exacerbated when individuals lose their identifiers (e.g., radio collars, tags, or leg bands; Milligan, Davis, \& Altizer, 2003) or when socially monogamous individuals participate in extra-pair parentage (e.g., Overbeek et al., 2020). Even in captivity, parentage amongst polygynous breeders is difficult to track. Individuals with unknown parentage are either excluded from the potential breeding population due to kinship uncertainty, are assigned a multiple parentage average kinship value (i.e., MULTs; Lacy, 2012), or are assigned with assumed parents (Ballou et al., 2010). Building MULTs into a pedigree has been shown to retain greater genetic diversity while still maintaining inbreeding avoidance as opposed to removing individuals of unknown parentage, as shown in Arabian oryx (Oryx leucoryx; Putnam \& Ivy, 2014). However, for species that experience large differences in reproductive success between individuals, the MULT approach has been shown to both over- and underestimate individual genetic contributions (e.g., Tasmanian devil; Farquharson, Hogg, \& Grueber, 2019). To highlight the severity of such challenges in group breeding species, over $50 \%$ of ungulate species managed under the auspices of the Association of Zoos and Aquariums Species Survival Plan ${ }^{\circledR}$ (SSP) have less than half of their pedigree known; in fact, only $15 \%$ have completely known pedigrees (R.M.Gooley and E.K.Latch, unpublished data). This is a common challenge encountered with group-housed captive populations, which can lead to management challenges with respect to kinship calculations, breeding recommendations, and genetic diversity retention (Hauser, Galla, Steeves, \& Latch, Preprint). Resolving unknown parentage and generating accurate kinship values would lead to more effective conservation management of intensively managed wild and captive populations.

To address pedigree challenges, molecular (e.g., genetic or genomic) estimates of relatedness from can be used to complete and complement pedigrees. For relatively diverse wild populations, microsatellite-based approaches can be informative (McLennan et al., 2018), especially for inferring close relatives. For example, a recent study from Moran et al., (2021) highlighted the benefit of using microsatellite markers to verify parentage in critically endangered California condor (Gymnogyps californianus). While microsatellites are useful, high density single nucleotide polymorphisms (i.e., SNPs) generated through high throughput sequencing approaches (i.e., HTS) often provide better resolution for estimating identity-by-descent, even when populations are inbred or relationships are more distant (Allendorf, Hohenlohe, \& Luikart, 2010; Taylor, 2015; Flanagan \& Jones 2019; Galla et al., 2020). Molecular data have been used to enhance pedigrees for use in conservation management, including estimating founder relationships (Hogg et al., 2019) and reconstructing pedigrees (Gooley, Hogg, Belov, \& Grueber, 2017; Huisman et al. 2017; McLennan et al., 2018) in Tasmanian devils and guiding metapopulation management of pedigreed and non-pedigreed populations of sable antelope (Hippotragus niger) and dama gazelle (Nanger dama; R.M.Gooley Personal comm.). Molecular data can also be used to validate uncertain and semi-wild pedigrees. For example, microsatellite markers have 
recently been used to validate pedigrees for intensively-monitored and critically endangered wild populations of kakī/black stilt (Himantopus novaezelandiae; Overbeek et al., 2020) and black robin (Petroica traversi; Forsdick, Cubrinovska, Massaro, \& Hale, 2021). Even when pedigrees are 'perfect' with no missing information and accurate parentage assignments, genomic data may capture more existing variation in realized relatedness between relatives, given the effects of recombination and segregation and random fertilisation (Speed \& Balding, 2015). However, the extent to which these differences impact conservation management decisions including pairing recommendations remains to be explored (Galla et al. 2020).

Fellow conservation practitioners and researchers have queried whether time and resources should be dedicated towards building pedigrees from scratch and maintaining them, considering their caveats and the abundance of HTS data available to produce estimates of relatedness that are comparable to pedigrees (Speed \& Balding, 2015). In this perspective, we argue that pedigrees remain an invaluable tool in the conservation genomics era, providing an affordable approach to estimate relatedness and inbreeding (Nietlisbach et al., 2017, but see also Kardos, Luikart, \& Allendorf, 2015), enhance genomic inquiry, and capture important metadata that genomic data alone cannot (Fig. 2). Based on our collective experience, we assert that gathering the behavioural and ecological data that underlie pedigrees not only advances our understanding of inter-individual relationships, but also develops strong ties between conservation geneticists, practitioners, and beyond (see below). In the conservation genomics era, we posit that the greatest conservation genomic advances will happen when we invest in both pedigree and genomic data.

\section{The value of pedigrees in the conservation genomics era}

\section{Beyond kinship: Demographic information \& 8 metadata captured in pedigrees}

Pedigrees capture a wealth of information beyond individual relationships produced purely by genomic data (Clutton-Brock \& Sheldon, 2010). The behavioral and ecological observations required to provide inter-individual relationships results in a rich ancillary dataset that cannot be captured by genomic data alone. For example, pedigrees can discern different relationships with identical relatedness coefficients (e.g., half-siblings compared to grandparent-grandoffspring, $R=0.25$ ), which can have different social and ecological consequences. Pedigrees also carry rich demographic data that may be inaccessible from molecular data, including sex for species without genetic sex determination (Janzen \& Paukstis, 1991), cohort, number of offspring, age, and survival. Information regarding number of offspring produced throughout a pedigree is valuable for understanding individual metrics of fitness and genetic contributions, as shown in Florida scrub jays (Chen et al. 2019), song-sparrows (Melospiza melodia; Reid, Nietlisbach, Wolak, Keller, \& Aarcese 2019), and Soay sheep (Ovis aries; Hunter, Pemberton, Pilkington, \& Morrissey 2019). In addition to demographic information, phenotypic data collected alongside ancestry is often extensive, including morphometrics (e.g., weight, size, body condition), cause of death, behaviour, and signs of inbreeding depression (e.g., disease susceptibility, infertility). On its own, the metadata captured alongside pedigrees can be used to forecast best management practices for small populations through population viability analysis (i.e., PVA; Lacy \& Pollak, 2021) and provides a critical resource for understanding demography and fitness (e.g., variance in reproductive success). We acknowledge that, in the absence of pedigree data, demographic data can be optionally collected independent of pedigrees along with genomic data for downstream analyses. However, these datasets rarely encompass the long-term sampling inherent in pedigree records, and may not be able to accurately capture key evolutionary parameters including individual fitness. In contrast, and by virtue of how pedigree data is collected and structured, the long-term demographic data associated with pedigrees is invaluable. For example, a recent study harnessed pedigree data from 15 species ( $>30 \mathrm{~K}$ individuals) to show how generations in captivity impact survival (Farquharson, Hogg, \& Grueber, 2021). Another study assessing breeding in 39 pedigreed populations of 21 wild animal species ( $>35 \mathrm{~K}$ females) concluded that many species were able to buffer annual fluctuations in optimal breeding date through phenotypic plasticity (de Villemereuil et al., 2020). Meta-analyses on this scale would be impossible to ascertain using genomic data alone, given these studies rely on life history data carried in pedigrees. Further, metadata readily captured in pedigrees can also be integrated with genomic approaches, for example the construction of linkage maps and quantitative trait locus mapping (Sewell, Sherman, \& Neale, 1999; Pelgas, Bousquet, Meirmans, Ritland, \& 
Isabel, 2011), genome-wide association studies (GWAS; Morris et al., 2013), assessing adaptive potential (de Villemereuil et al., 2019a), genomic selection (GS) studies, and GxE studies to test genotypes for association with environmental variation (Crossa et al., 2017; see below).

\section{Pedigrees complement genomic study design and inference}

The relationship information and metadata captured by pedigrees are an invaluable tool to help design and implement genomic research. For example, pedigrees provide biologically-relevant data to inform a non-biased selection of individuals for building representative and high-quality reference genomes. When selecting an individual for a reference genome for species with genetic sex determination, some researchers have preferred selecting either the homogametic sex to ensure adequate coverage of the homogametic sex chromosome (i.e., $\mathrm{X}$ or $\mathrm{Z}$ ), or the heterogametic sex to capture the alternative and often highly repetitive sex chromosome (i.e., Y or W; Tomaszkiewicz, Medvedev, \& Makova, 2017; Rhie et al., 2021). In addition to helping select the candidates for sampling based on sex, pedigrees can also identify individuals that are likely to be highly inbred, which assists with genome assembly by reducing error associated with ambiguity between heterozygosity and genetic paralogues (Hahn, Zhang, and Moyle 2014; Rhie et al., 2021). Further, detailed pedigrees can enable selection of parent-offspring trios to generate phased de novo genome assemblies (Korbel \& Lee, 2013; Koren et al., 2018; Leitwein, Duranton, Rougemont, Gagnaire, \& Bernatchez, 2020). Highquality de novo reference genomes are a powerful resource for the conservation and evolutionary genomics community by facilitating read mapping (Card et al., 2014), mining for genes of interest (e.g., Greenhalgh et al., 2021), and SNP discovery and genotyping (e.g., Galla et al., 2019; Brandies, Peel, Hogg, \& Belov, 2019; Gooley et al., 2020). To further characterise variants across the genome, including structural variants (SVs), pedigrees may be used to inform the curation of a pangenome, which is the assembly of multiple individuals with the aim to capture all standing genomic diversity in a population or species of interest (Tettelin et al. 2005; Brockhurst et al., 2019). In this instance, a pedigree can be leveraged to identify distantly related individuals to ensure the pangenome is representative (Wold et al. 2021). Finally, pedigree-based linkage maps have been a valuable resource for scaffolded genome assemblies by enabling higher assembly accuracy, order, and contiguity (Catchen, Amores, \& Bassham 2020).

Pedigree data is also an invaluable resource for selecting individuals for resequencing (i.e., whole genome resequencing, or WGS). For example, a pedigree can inform the choice of closely related family groups for genomic inquiry (e.g., Galla et al., 2020), understanding characterized phenotypes of interest (Nersisyan, Nikoghosyan, \& Arakelyan, 2019), or when maximizing representative genomic diversity across a species (Robinson et al., 2021). In the case of sable antelope (Hippotragus niger; Gooley et al., 2020) the software program PedSam (https://sites.uwm.edu/latch/software-2/) was used to streamline the selection of individuals representative of founder diversity across many managed populations for downstream diversity comparisons. In a recent study in California condors, individuals with low inbreeding and kinship coefficients were selected using the pedigree, and were compared in terms of runs of homozygosity using WGS (Robinson et al., 2021). When familial relationships are known via pedigrees, this information can also be used to validate whether molecular approaches (e.g., extraction, amplification, library preparation, or sequencing) produce data that are consistent with biologically-relevant expectations or experienced error along the way (see Galla et al., 2020 for details).

Beyond informing the individuals sampled for molecular studies, pedigrees can be pivotal to successful genetic variant discovery. For many conservation genomic research projects, variants (e.g., SNPs, SVs) are used as markers to identify and measure diversity (Hohenlohe, Funk, \& Rajora, 2020; Wold et al., 2021). Artefacts from library preparation, sequencing, and bioinformatic processing can lead to false variants in datasets, which can bias downstream analyses (O'Leary, Puritz, Willis, Hollenbeck, \& Portnoy, 2018). In addition to adequate filtering for sequencing depth and Hardy-Weinberg equilibrium, validated pedigrees can be used as one tool for filtering false datasets from variants using Mendelian inheritance. This approach has long been used in the field of human genetics for marker validation, and in one study, was able to reduce marker error rates by $50 \%$ (Chen et al., 2013). A study in the pedigreed population of Florida scrub jays shows great promise for this approach, identifying sex-linked and false SNPs from a 
reduced representation data set (Chen, Van Hout, Gottipati, \& Clark, 2014). Further, variant discovery for the critically endangered kākāpō is being informed by Mendelian inheritance, creating a high quality variant data set for all individuals of this species (Joseph Guhlin, Personal comm.). Because genomic research for species of conservation concern is often budget-constrained, datasets are often hampered by low sequencing depth and subsequent missing data. In the fields of human and crop genetics, imputation (e.g., completing missing data sets with likely alleles using algorithms) is one option for addressing large amounts of missing data (Hickey, Kinghorn, Tier, van der Werf, \& Cleveland, 2012; Sargolzaei, Chesnais, \& Schenkel, 2014). When coupled with genotypic information from family groups, this approach can increase the likelihood of accurate imputation, even of rare alleles (Ullah et al., 2019). We anticipate imputation - despite its caveats (see Roshyara et al. 2014) - will be explored more in the field of conservation genomics, especially for species with large genomes that are costly to sequence at high depths (e.g., some fish, insects, and plants; Mao et al., 2020) or as a cost-effective option for conservation programs that can only sequence at low depths.

\section{Pedigrees and Quantitative Genetics}

Even in the absence of molecular information, pedigrees have long provided an understanding of the genetic basis of phenotypic differences between individuals in a population, the selective pressures on these traits, and evolutionary potential (e.g. Farquharson et al., 2017). Quantitative genetic models leverage variation in pedigree-based relatedness between individuals to estimate the proportion of trait variation that is due to genetic differences between individuals (i.e., heritability; often estimated from complex pedigrees using a mixed effects statistical model termed the 'animal model', Wilson et al., 2010). In general, high heritabilities enable populations to evolve more quickly in response to selection, which is a valuable characteristic for threatened populations experiencing strong selection pressures due to rapid global change (Woodruff, 2001). For example, a recent study in hihi (Notiomystis cincta) used pedigree-based heritability to reveal low evolutionary potential in this threatened bird (de Villemereuil et al., 2019a). In addition to heritability, known family groups or distinct populations have also been essential to understanding GxE interactions, especially in plant species (Bisbing et al., 2020; Yoko, Volk, Dochtermann, \& Hamilton, 2020). Empirical estimates of relatedness can be used instead of pedigrees, and may overcome pedigree pitfalls while providing realized estimates of genome-sharing (Hill \& Weir, 2011; Hill \& Weir 2012; Speed \& Balding, 2015). However, genomic approaches often fail to account for important confounding effects which pedigrees naturally capture, including maternal and cohort effects (e.g., de Villemereuil, Rutschmann, Ewen, Santure, \& Brekke, 2019b) that may lead to biased estimates of heritability and evolutionary potential. Further, the one-off design of many genomic studies, compared to the longer-term monitoring required to capture pedigree relationships, is only likely to capture genotyped individuals across one or a few years. As a consequence, environmental variability in space and time is not always accurately captured, which in turn can also lead to inaccuracies in predicting selection response. Finally, heritability models require large sample sizes (e.g., hundreds to thousands of individuals) to produce precise estimates of heritability (de Villemereuil, 2012). While genomic relatedness may be constructed for thousands of individuals, pedigrees provide a cost-effective approach for sampling IBD across more individuals over time.

Methods that identify the regions of the genome that contribute to trait heritability, broadly termed 'gene mapping', often require or are enhanced by pedigree information. Linkage mapping is one important method of gene mapping, which leverages genetic markers, phenotypic data, and recombination across a multi-generational pedigree to understand the general location of genes controlling traits (Slate et al., 2009; Laird \& Lange, 2011). Tracking dense panels of genome-wide markers over generations also forms the basis of genetic linkage maps, which characterise the recombination landscape and show the position and order of genes throughout the genome. For example, a linkage map was created for collared flycatcher (Ficedula albicollis) using deep pedigree data and thousands of genome-wide SNPs, which has provided an understanding of flycatcher genome architecture in comparison to other species (Kawakami et al., 2014). Beyond providing an understanding of genome evolution, these maps provide useful context to how populations are expected to respond to selection pressures (Stapley, Feulner, Johnston, Santure, \& Smadja, 2017). For example, mapping resources and pedigrees developed in California condor are being used to understand the genomic basis of chondrodystrophy, a lethal form of dwarfism in this critically 
endangered species (Ralls, Ballou, Rideout, \& Frankham, 2000; Romanov et al., 2009). Besides traits that are controlled by single genes of large effect, linkage maps and pedigree data can be utilised for quantitative trait locus linkage mapping, or QTL mapping, which enables the detection of many genomic loci that contribute to continuous trait differences (Slate, 2005). For example, QTL mapping identified candidate adaptive loci contributing to bud phenology in white spruce (Picea glauca; Pelgas et al., 2011) and phenotypic differences between marine and freshwater nine-spined stickleback (Pungitius pungitius; Yang, Guo, Shikano, Liu, \& Merilä, 2016). Similarly, pedigree information can be incorporated into GWAS, which leverages dense markers, putatively unrelated individuals, and phenotypic information to understand the genomic basis of traits. For example, pedigree data can be combined with GWAS to partition direct and indirect genetic effects on phenotypes of interest, as opposed the GWAS alone which combines these effects (Young, Benonisottir, Prezeworski, \& Kong, 2019). In doing so, a pedigree-informed GWAS provides an unbiased way to study genetic effects and response to selection. Studies have also shown that GWAS that incorporate pedigree data are better able to avoid type-I error and add greater precision to GWAS analyses, especially in data sets with low marker density (Chen et al., 2013; Zhou et al., 2017).

Pedigrees are a bridge between researchers, practitioners, and Indigenous Peoples and Local Communities

Pedigrees are a useful tool for understanding genetics and informing management efforts for threatened species. Beyond these uses, we contend that pedigrees help bridge the gap between conservation research and practice (i.e., the 'research-implementation gap' or the 'conservation genomics gap'; Knight et al., 2008; Shafer et al., 2015). Collating and refining pedigree data is a time consuming task that often requires strong communication between practitioners who collect long-term demographic data sets and researchers who help validate pedigrees and perform downstream analyses. Indeed, the act of building a pedigree requires mutual knowledge of species life history, genealogy, and the genetic data used for validation. This co-development of pedigree resources builds trust, which can translate into improved application of genetic and genomic research into the conservation management of threatened species (Box 1).

In illustrating connections that link the present to the past, pedigrees are well-aligned with both Indigenous and non-Indigenous worldviews (Hudson, Ahuriri-Driscoll, Lea \& Lea, 2007; Collier-Robinson, Rayne, Rupene, Thoms, \& Steeves 2019; Hudson et al., 2020). Given this alignment, pedigrees can provide a centerpoint for discussions with Indigenous decision makers regarding conservation genetics research of culturally significant species (Box 2). Further, in our experience working with Indigenous Peoples and Local Communities (IPLC) to enhance the recovery of threatened taonga (treasured) species in Aotearoa New Zealand, discussing familial ties between individuals provides opportunities for all parties to share diverse knowledge regarding these individuals as well as the environments around them. Given this, we encourage researchers to consider the use of pedigrees to help build mutually beneficial relationships with IPLC.

We have also found that pedigrees provide a helpful visual to communicate fundamental conservation genetics concepts like relatedness, inbreeding, and heritability without jargon to non-scientific audiences, in large part because pedigrees are relatable. Indeed, our collective co-authorship has had experience using pedigrees-generally presented as family trees-as highly effective tools for engaging with school groups, university classrooms, retirees, policy makers, and politicians regarding conservation genetic management of threatened species. Effective science communication enhances conservation outcomes (see Holderegger et al., 2019), and we are confident that pedigrees will remain an important tool for science communicators for years to come.

\section{A conservation genomic powerhouse}

While pedigrees are one of the most long-standing tools in the conservation genetics toolbox, when coupled with unprecedented advances in genetics and genomics, they create a powerhouse for conservation management capable of better characterizing and preserving diversity in a changing world. Robust pedigrees - that can be complemented and completed with molecular data - continue to provide long-term demographic and life history information that allow for improved research design and implementation, and provide opportunities to build and maintain trusted relationships. We contend that pedigrees will remain relevant 
for applied and fundamental research, and advocate for their maintenance in programs across the ex situ and in situ management spectrum.

For those beginning to assemble pedigree data, we offer the following advice for maximum success. First, when establishing a new pedigree of plants or animals, collect tissue samples and metadata (e.g., phenotypic information and geographic provenance) for as many individuals as possible (including all founders, in the case of conservation breeding programs) to ensure you can inform inter-individual relationships. In addition to initial sampling, we recommend maintaining detailed metadata (e.g., date of birth, sex, morphometrics of interest, cause of death) and tissue samples for all pedigreed individuals in subsequent generations. Tissue banks for all pedigreed individuals can help jumpstart genomic research, coupled with collected metadata embedded in the pedigree. Tissue samples can also be used by conservation genetic researchers to periodically validate the pedigree for accuracy and assist with any uncertain parentage assignments. Finally, we advocate for clear communication between researchers, practitioners, and IPLC to ensure pedigrees continue to be built and used as a tool for management for generations to come.

\section{Acknowledgements}

We thank all members of the Kākāpō, Kākāriki Karaka, and Kakī Recovery Programmes-including the Ngāi Tahu representatives on the Recovery Groups for each of these taonga (treasured) species-for their support and inspiration for this manuscript. We are thankful to Dr. Robert C. Lacy who provided a friendly review of an early draft of this manuscript. We are grateful to Dr. Aisling Rayne, who provided helpful context and citations for Box 2. We thank Dr. Jennifer S. Forbey for her feedback and support. We gratefully acknowledge Petrus Hedman for his kākāpō photo, Leonie Hayder for her kākāriki karaka photo, and LB for her kakī photo in Box 1. This work has been funded by the Ministry of Business, Innovation and Employment (MBIE) Endeavour Fund (UOCX1602 awarded to TES) and was supported by the NSF Track 2 EPSCoR Program (OIA-1826801 awarded to Jennifer S. Forbey and MA Matocq) and a SERDP award (RC-2702, awarded to JA Heath).

\section{References}

Åkesson, M., Liberg, O., Sand, H., Wabakken, P., Bensch, S., \& Flagstad, Ø. (2016). Genetic rescue in a severely inbred wolf population. Molecular Ecology, 25(19),4745-4756. doi: /10.1111/mec.13797

Allendorf, F. W., Hohenlohe, P. A., \& Luikart, G. (2010). Genomics and the future of conservation genetics. Nature Reviews Genetics, $11(10), 697-709$.

Ashley, M. V. (2010). Plant parentage, pollination, and dispersal: how DNA microsatellites have altered the landscape. Critical Reviews in Plant Sciences, 29(3), 148-161. doi: /10.1080/07352689.2010.481167

Avise, J. C. (2008). The history, purview, and future of conservation genetics. Conservation biology: evolution in action, $5-15$.

Ballou, J. (1983). Calculating inbreeding coefficients from pedigrees. Genetics and conservation: a reference for managing wild animal and plant populations, 509, 520 .

Ballou, J. D., Lees, C., Faust, L. J., Long, S., Lynch, C., Bingaman Lackey, L., \& Foose, T. J. (2010). Demographic and genetic management of captive populations. Wild mammals in captivity: principles and techniques for zoo management, 219.

Balloux, F., Amos, W., \& Coulson, T. (2004). Does heterozygosity estimate inbreeding in real populations? Molecular Ecology, 13(10), 3021- 3031. doi: /10.1111/j.1365-294X.2004.02318.x

Bennett, R. L. (2011). The practical guide to the genetic family history. John Wiley \& Sons.

Bergner, L. M., Jamieson, I. G., \& Robertson, B. C. (2014). Combining genetic data to identify relatedness among founders in a genetically depauperate parrot, the Kakapo (Strigops habroptilus). Conservation Genetics, 15(5), 1013-1020. doi: /10.1007/s10592-014-0595-y 
Bisbing, S.M., A.K. Urza, B.J. Buma, D.J. Cooper, M. Matocq, A.L. Angert. 2020. Can long-lived species keep pace with climate change? Evidence of local persistence potential in a widespread conifer. Diversity and Distributions, 27(2): 296-312. doi: /10.1111/ddi.13191

Boardman, K., Mace, M., Peregoy, S., Ivy, J. A. (2017). Population analysis \& breeding transfer plan, whooping crane (Grus americana). AZA Species Survival Plan@ Program. Population Management Center, Association of Zoos and Aquariums, Silver Spring, MD, 36 pp.

Brandies, P., Peel, E., Hogg, C. J., \& Belov, K. (2019). The value of reference genomes in the conservation of threatened species. Genes, 10(11), 846. doi: /10.3390/genes10110846

Brockhurst, M. A., Harrison, E., Hall, J. P., Richards, T., McNally, A., \& MacLean, C. (2019). The ecology and evolution of pangenomes. Current Biology, 29(20), R1094-R1103. doi: /10.1016/j.cub.2019.08.012

Card, D. C., Schield, D. R., Reyes-Velasco, J., Fujita, M. K., Andrew, A. L., Oyler-McCance, S. J., .. \& \& Castoe, T. A. (2014). Two low coverage bird genomes and a comparison of reference-guided versus de novo genome assemblies. PLoS One, 9(9), e106649. doi: /10.1371/journal.pone.0106649

Catchen, J., Amores, A., \& Bassham, S. (2020). Chromonomer: a tool set for repairing and enhancing assembled genomes through integration of genetic maps and conserved synteny. G3: Genes, Genomes, Genetics, 10(11), 4115-4128.

Chambers, J. M., Wyborn, C., Ryan, M. E., Reid, R. S., Riechers, M., Serban, A., .. \& \& Pickering, T. (2021). Six modes of co-production for sustainability. Nature Sustainability, 1-14.

Chen, W., Li, B., Zeng, Z., Sanna, S., Sidore, C., Busonero, F., . . \& Abecasis, G. R. (2013). Genotype calling and haplotyping in parent-offspring trios. Genome Research, 23(1), 142-151. doi: /10.1101/gr.142455.112

Chen, N., Van Hout, C. V., Gottipati, S., \& Clark, A. G. (2014). Using Mendelian inheritance to improve high-throughput SNP discovery. Genetics, 198(3), 847-857. doi: /10.1534/genetics.114.169052

Chen, N., Juric, I., Cosgrove, E. J., Bowman, R., Fitzpatrick, J. W., Schoech, S. J., . . \& Coop, G. (2019). Allele frequency dynamics in a pedigreed natural population. Proceedings of the National Academy of Sciences, 116 (6), 2158-2164. doi: /10.1073/pnas.1813852116

Clutton-Brock, T., \& Sheldon, B. C. (2010). Individuals and populations: the role of long-term, individualbased studies of animals in ecology and evolutionary biology. Trends in Ecology $\&$ Evolution, 25 (10), 562-573. doi: $/ 10.1016 /$ j.tree.2010.08.002

Coimbra, M. R., Dantas, H. L., Luna, M. M., Lima, M. A., Sales, M., da Silva, B. C., \& Lima, A. P. (2020). High gene flow in two migratory Neotropical fish species, Salminus franciscanus and Brycon orthotaenia, and implications for conservation aquaculture. Aquatic Conservation: Marine and Freshwater Ecosystems, 30(6), 1063-1073. doi: /10.1002/aqc.3336

Coimbra, R. T., Winter, S., Kumar, V., Koepfli, K. P., Gooley, R. M., Dobrynin, P., .. \& Janke, A. (2021). Whole-genome analysis of giraffe supports four distinct species. Current Biology, 31, 1-10. doi: /10.1016/j.cub.2021.04.033.

Collier-Robinson, L., Rayne, A., Rupene, M., Thoms, C., \& Steeves, T. (2019). Embedding indigenous principles in genomic research of culturally significant species: a conservation genomics case study. New Zealand Journal of Ecology, 43(3), 1-9. doi: /10.20417/nzjecol.43.36

Crossa, J., Pérez-Rodríguez, P., Cuevas, J., Montesinos-López, O., Jarquín, D., de los Campos, G., ... \& Varshney, R. K. (2017). Genomic selection in plant breeding: methods, models, and perspectives. Trends in Plant Science, 22(11), 961-975. doi: /10.1016/j.tplants.2017.08.011

DeCandia, A. L., Schrom, E. C., Brandell, E. E., Stahler, D. R., \& vonHoldt, B. M. (2021). Sarcoptic mange severity is associated with reduced genomic variation and evidence of selection in Yellowstone National Park wolves (Canis lupus). Evolutionary Applications, 14(2), 429-445. doi: /10.1111/eva.1312712 
de Villemereuil, P. (2012). Tutorial Estimation of a biological trait heritability using the animal model: How to use the MCMCglmm R package. https://devillemereuil.legtux.org/wp-content/uploads/2012/12/tuto_en.pdf

de Villemereuil, P., Rutschmann, A., Lee, K. D., Ewen, J. G., Brekke, P., \& Santure, A. W. (2019a). Little adaptive potential in a threatened passerine bird. Current Biology, 29(5), 889-894. doi: /10.1016/j.cub.2019.01.072.

de Villemereuil, P., Rutschmann, A., Ewen, J. G., Santure, A. W., \& Brekke, P. (2019b). Can threatened species adapt in a restored habitat? No expected evolutionary response in lay date for the New Zealand hihi. Evolutionary Applications, 12(3), 482-497. doi: /10.1111/eva.12727.

de Villemereuil, P., Charmantier, A., Arlt, D., Bize, P., Brekke, P., Brouwer, L., .. \& Chevin, L. M. (2020). Fluctuating optimum and temporally variable selection on breeding date in birds and mammals. Proceedings of the National Academy of Sciences, 117(50), 31969-31978. doi: /10.1073/pnas.2009003117

Di Santo, L. N., \& Hamilton, J. A. (2020). Using environmental and geographic data to optimize ex situ collections and preserve evolutionary potential. Conservation Biology, 35(2), 733-744. doi: /10.1111/cobi.13568

Farquharson, K. A., Hogg, C. J., \& Grueber, C. E. (2017). Pedigree analysis reveals a generational decline in reproductive success of captive Tasmanian devil (Sarcophilus harrisii): implications for captive management of threatened species. Journal of Heredity, 108(5), 488-495. doi: /10.1093/jhered/esx030

Farquharson, K. A., Hogg, C. J., \& Grueber, C. E. (2019). A case for genetic parentage assignment in captive group housing. Conservation Genetics, 20(5), 1187-1193. doi: /10.1007/s10592-019-01198-w

Farquharson, K. A., Hogg, C. J., \& Grueber, C. E. (2021). Offspring survival changes over generations of captive breeding. Nature Communications, 12(1), 1-9. doi: /10.1038/s41467-021-22631-0

Faust, L. J., Bergstrom, Y. M., Thompson, S. D., \& Bier, L. (2019). PopLink Version 2.5. Lincoln Park Zoo. Chicago, IL. https://www.lpzoo.org/science-project/poplink/

Flanagan, S. P., \& Jones, A. G. (2019). The future of parentage analysis: From microsatellites to SNPs and beyond. Molecular Ecology, 28(3), 544-567. doi: /10.1111/mec.14988

Forsdick, N. J., Cubrinovska, I., Massaro, M., \& Hale, M. L. (2021). Microsatellite genotyping detects extrapair paternity in the Chatham Island Black Robin, a highly inbred, socially monogamous passerine. Emu Austral Ornithology, 121:68-74, doi: 10.1080/01584197.2020.1812406

Galla, S. J. (2019) Conservation genomic management of two critically endangered New Zealand birds. Thesis for Doctor of Philosophy in Biological Sciences, University of Canterbury. doi:/10.26021/8081

Galla, S. J., Forsdick, N. J., Brown, L., Hoeppner, M. P., Knapp, M., Maloney, R. F., .. \& Steeves, T. E. (2019). Reference genomes from distantly related species can be used for discovery of single nucleotide polymorphisms to inform conservation management. Genes, 10(1), 9. doi: /10.3390/genes10010009

Galla, S. J., Moraga, R., Brown, L., Cleland, S., Hoeppner, M. P., Maloney, R. F., . . \& Steeves, T. E. (2020). A comparison of pedigree, genetic and genomic estimates of relatedness for informing pairing decisions in two critically endangered birds: Implications for conservation breeding programmes worldwide. Evolutionary Applications, 13(5), 991-1008. doi: /10.1111/eva.12916

George, J. P., Theroux-Rancourt, G., Rungwattana, K., Scheffknecht, S., Momirovic, N., Neuhauser, L., ... \& Hietz, P. (2020). Assessing adaptive and plastic responses in growth and functional traits in a 10-year-old common garden experiment with pedunculate oak (Quercus robur L.) suggests that directional selection can drive climatic adaptation. Evolutionary applications, 13(9), 2422-2438. doi: /10.1111/eva.13034

Giglio, R. M., Ivy, J. A., Jones, L. C., \& Latch, E. K. (2016). Evaluation of alternative management strategies for maintenance of genetic variation in wildlife populations. Animal Conservation, 19(4), 380-390. https://doi.org/10.1111/acv.12254 
Giglio, R. M., Ivy, J. A., Jones, L. C., \& Latch, E. K. (2018). Pedigree-based genetic management improves bison conservation. The Journal of Wildlife Management, 82(4), 766-774. https://doi.org/10.1002/jwmg.21433

Gooley, R., Hogg, C. J., Belov, K., \& Grueber, C. E. (2017). No evidence of inbreeding depression in a Tasmanian devil insurance population despite significant variation in inbreeding. Scientific Reports, 7(1), 1-11. doi: /10.1038/s41598-017-02000-y

Gooley, R. M., Tamazian, G., Castaneda-Rico, S., Murphy, K. R., Dobrynin, P., Ferrie, G. M., .. \& Koepfli, K. P. (2020). Comparison of genomic diversity and structure of sable antelope (Hippotragus niger) in zoos, conservation centers, and private ranches in North America. Evolutionary Applications, 13(8), 2143-2154. doi: /10.1111/eva.12976

Greenhalgh, R., Holding, M. L., Orr, T. J., Henderson, J. B., Parchman, T. L., Matocq, M. D., .. \& Dearing, M. D. (2021). Trio-binned genomes of the woodrats Neotoma bryanti and N. lepida reveal novel gene islands and rapid copy number evolution of xenobiotic metabolizing cytochrome p450 genes. bioRxiv. doi: /10.1101/2021.03.08.434435

Grueber, C. E., \& Jamieson, I. G. (2008). Quantifying and managing the loss of genetic variation in a free-ranging population of takahe through the use of pedigrees. Conservation Genetics, 9(3), 645-651. doi: $/ 10.1007 / \mathrm{s} 10592-007-9390-3$

Hamilton, J., Flint, S., Lindstrom, J., Volk, K., Shaw, R., \& Ahlering, M. (2020). Evolutionary approaches to seed sourcing for grassland restorations. New Phytologist, 225 (6), 2246-2248. doi: /10.1111/nph.16427

Hammerly, S. C., de la Cerda, D. A., Bailey, H., \& Johnson, J. A. (2016). A pedigree gone bad: increased offspring survival after using DNA-based relatedness to minimize inbreeding in a captive population. Animal Conservation, 19(3), 296-303. doi: /10.1111/acv.12247

Hahn, M. W., Zhang, S. V., \& Moyle, L. C. (2014). Sequencing, assembling, and correcting draft genomes using recombinant populations. G3: Genes, Genomes, Genetics, 4(4), 669-679. doi: /10.1534/g3.114.010264

Hauser, S. S., Galla, S. J., Steeves, T. E., Latch, E. K. (Preprint). Comparing genomic-based estimates of relatedness for use in pedigree-based conservation management. BioRxiv. doi: 10.1101/2021.07.08.451704.

Hickey, J. M., Kinghorn, B. P., Tier, B., van der Werf, J. H., \& Cleveland, M. A. (2012). A phasing and imputation method for pedigreed populations that results in a single-stage genomic evaluation. Genetics Selection Evolution, 44(1), 1-11. doi: /10.1186/1297-9686-44-9

Hill, W. G., \& Weir, B. S. (2011). Variation in actual relationship as a consequence of Mendelian sampling and linkage. Genetics Research, 93(1), 47-64. doi:/10.1017/S0016672310000480

Hill, W. G., \& Weir, B. S. (2012). Variation in actual relationship among descendants of inbred individuals. Genetics Research, 94(5), 267-274. doi: /10.1017/S0016672312000468

Hoelzel, A. R., Bruford, M. W., \& Fleischer, R. C. (2019). Conservation of adaptive potential and functional diversity. Conservation Genetics 20:1-5. doi: /10.1007/s10592-019-

Hogg, C. J., Wright, B., Morris, K. M., Lee, A. V., Ivy, J. A., Grueber, C. E., \& Belov, K. (2019). Founder relationships and conservation management: empirical kinships reveal the effect on breeding programmes when founders are assumed to be unrelated. Animal Conservation, 22(4), 348-361. doi: /10.1111/acv.12463

Hogg, J. T., Forbes, S. H., Steele, B. M., \& Luikart, G. (2006). Genetic rescue of an insular population of large mammals. Proceedings of the Royal Society B: Biological Sciences, 273(1593), 1491-1499. doi: /10.1098/rspb.2006.3477

Holderegger, R., Balkenhol, N., Bolliger, J., Engler, J. O., Gugerli, F., Hochkirch, A., .. \& Zachos, F. E. (2019). Conservation genetics: Linking science with practice. Molecular Ecology, 28(17):2848-3856. doi: $/ 10.1111 /$ mec. 15202 
Hohenlohe, P. A., Funk, W. C., \& Rajora, O. P. (2021). Population genomics for wildlife conservation and management. Molecular Ecology, 30(1), 62-82. doi: /10.1111/mec.15720

Hudson, M. L., Ahuriri-Driscoll, A. L., Lea, M. G., \& Lea, R. A. (2007). Whakapapa-a foundation for genetic research? Journal of Bioethical Inquiry, 4(1), 43-49.

Hudson, M., Nanibaa'A, G., Sterling, R., Caron, N. R., Fox, K., Yracheta, J., . . \& Carroll, S. R. (2020). Rights, interests and expectations: Indigenous perspectives on unrestricted access to genomic data. Nature Reviews Genetics, 21(6), 377-384.

Huisman, J. (2017). Pedigree reconstruction from SNP data: parentage assignment, sibship clustering and beyond. Molecular Ecology Resources, 17(5), 1009-1024.

Hunter, D. C., Pemberton, J. M., Pilkington, J. G., \& Morrissey, M. B. (2019). Pedigree-based estimation of reproductive value. Journal of Heredity, 110(4), 433-444.

Ivy, J. A., Miller, A., Lacy, R. C., \& DeWoody, J. A. (2009). Methods and prospects for using molecular data in captive breeding programs: an empirical example using parma wallabies (Macropus parma). Journal of Heredity, 100(4), 441-454. doi: /10.1093/jhered/esp019

Ivy, J. A., Putnam, A. S., Navarro, A. Y., Gurr, J., \& Ryder, O. A. (2016). Applying SNP-derived molecular coancestry estimates to captive breeding programs. Journal of Heredity, 107(5), 403-412. doi: /10.1093/jhered/esw029

Janzen, F. J., \& Paukstis, G. L. (1991). Environmental sex determination in reptiles: ecology, evolution, and experimental design. The Quarterly Review of Biology, 66 (2), 149-179. doi: 10.1086/417143.

Kardos, M., Luikart, G., \& Allendorf, F. W. (2015). Measuring individual inbreeding in the age of genomics: marker-based measures are better than pedigrees. Heredity, 115(1), 63-72. doi: /10.1038/hdy.2015.17

Kawakami, T., Smeds, L., Backstrom, N., Husby, A., Qvarnstrom, A., Mugal, C. F., .. \& Ellegren, H. (2014). A high-density linkage map enables a second-generation collared flycatcher genome assembly and reveals the patterns of avian recombination rate variation and chromosomal evolution. Molecular Ecology, 23(16), 4035-4058.

Knight, A. T., Cowling, R. M., Rouget, M., Balmford, A., Lombard, A. T., \& Campbell, B. M. (2008). Knowing but not doing: selecting priority conservation areas and the research-implementation gap. Conservation Biology, 22(3), 610-617. doi: /10.1111/j.1523-1739.2008.00914.x

Korbel, J. O., \& Lee, C. (2013). Genome assembly and haplotyping with Hi-C. Nature Biotechnology, 31(12), 1099-1101. doi: /10.1038/nbt.2764.

Koren, S., Rhie, A., Walenz, B. P., Dilthey, A. T., Bickhart, D. M., Kingan, S. B., .. \& \& Phillippy, A. M. (2018). De novo assembly of haplotype-resolved genomes with trio binning. Nature Biotechnology, 36(12), 1174-1182. doi: /10.1038/nbt.4277

Kruuk, L. E. B., \& Hill, W. G. (2008). Introduction. Evolutionary dynamics of wild populations: the use of long-term pedigree data. Proceedings of the Royal Society of London B, 275(1635), 593-596. doi: /10.1098/rspb.2007.1689

Lacy, R. C. (1995). Clarification of genetic terms and their use in the management of captive populations. Zoo Biology, 14(6), 565-577. doi: /10.1002/zoo.1430140609

Lacy, R.C. (2009). Stopping evolution: Genetic management of captive populations. Pages 58-81 in: G. Amato, R. DeSalle, O.A. Ryder, and H.C. Rosenbaum. Conservation genetics in the age of genomics. Columbia University Press, New York.

Lacy, R. C. (2012). Extending pedigree analysis for uncertain parentage and diverse breeding systems. Journal of Heredity, 103(2), 197-205. 
Lacy, R. C., Ballou, J. D., \& Pollak, J. P. (2012). PMx: software package for demographic and genetic analysis and management of pedigreed populations. Methods in Ecology and Evolution, 3(2), 433-437. doi: /10.1111/j.2041-210X.2011.00148.x

Lacy, R. C., \& Pollak, J.P. (2021). Vortex: A stochastic simulation of the extinction process. Version 10.5.5. Chicago Zoological Society, Brookfield, Illinois, USA.

Laird, N. M., \& Lange, C. (2011). The general concepts of gene mapping: Linkage, association, linkage disequilibrium and marker maps. In The Fundamentals of Modern Statistical Genetics (pp. 67-86). Springer, New York, NY.

Leitwein, M., Duranton, M., Rougemont, Q., Gagnaire, P. A., \& Bernatchez, L. (2020). Using haplotype information for conservation genomics. Trends in Ecology 83 Evolution, 35(3), 245-258. doi: /10.1016/j.tree.2019.10.012

Mable, B. K. (2019). Conservation of adaptive potential and functional diversity: integrating old and new approaches. Conservation Genetics, 20(1), 89-100. doi: /10.1007/s10592-018-1129-9

MacCluer, J. W., VandeBerg, J. L., Read, B., \& Ryder, O. A. (1986). Pedigree analysis by computer simulation. Zoo Bology, 5(2), 147-160.

Mao, Y., Zhang, N., Nie, Y., Zhang, X., Li, X., \& Huang, Y. (2020). Genome Size of 17 Species From Caelifera (Orthoptera) and Determination of Internal Standards With Very Large Genome Size in Insecta. Frontiers in Physiology, 11, 1321. doi: /10.3389/fphys.2020.567125

Martin, S. A., Lipps Jr, G. J., \& Gibbs, H. L. (2021). Pedigree-based assessment of recent population connectivity in a threatened rattlesnake. Molecular Ecology Resources, $21: 1820-1832$. doi: 10.1111/17550998.13383

McLennan, E. A., Gooley, R. M., Wise, P., Belov, K., Hogg, C. J., \& Grueber, C. E. (2018). Pedigree reconstruction using molecular data reveals an early warning sign of gene diversity loss in an island population of Tasmanian devils (Sarcophilus harrisii). Conservation Genetics, 19(2), 439-450. doi: /10.1007/s10592017-1017-8

McLennan, E. A., Grueber, C. E., Wise, P., Belov, K., \& Hogg, C. J. (2020). Mixing genetically differentiated populations successfully boosts diversity of an endangered carnivore. Animal Conservation, 23(6), 700-712. doi: /10.1111/acv.12589

Milligan, J. L., Davis, A. K., \& Altizer, S. M. (2003). Errors associated with using colored leg bands to identify wild birds. Journal of Field Ornithology, 74 (2), 111-118. doi: /10.1648/0273-8570-74.2.111

Moran, B. M., Thomas, S. M., Judson, J. M., Navarro, A., Davis, H., Sidak-Loftis, L., .. \& \& Steiner, C. C. (2021). Correcting parentage relationships in the endangered California Condor: Improving mean kinship estimates for conservation management. Ornithological Applications, 123, 1-13. doi: 10.1093/ornithapp/duab017

Morris, G. P., Ramu, P., Deshpande, S. P., Hash, C. T., Shah, T., Upadhyaya, H. D., .. \& Kresovich, S. (2013). Population genomic and genome-wide association studies of agroclimatic traits in sorghum. Proceedings of the National Academy of Sciences, 110(2), 453-458. doi: /10.1073/pnas.1215985110

Nietlisbach, P., Keller, L. F., Camenisch, G., Guillaume, F., Arcese, P., Reid, J. M., \& Postma, E. (2017). Pedigree-based inbreeding coefficient explains more variation in fitness than heterozygosity at 160 microsatellites in a wild bird population. Proceedings of the Royal Society B: Biological Sciences, 284 (1850), 20162763. doi: /10.1098/rspb.2016.2763

Nersisyan, L., Nikoghosyan, M., \& Arakelyan, A. (2019). WGS-based telomere length analysis in Dutch family trios implicates stronger maternal inheritance and a role for RRM1 gene. Scientific Reports, 9(1), 1-9. doi: /10.1038/s41598-019-55109-7 
O'Leary, S. J., Puritz, J. B., Willis, S. C., Hollenbeck, C. M., \& Portnoy, D. S. (2018). These aren't the loci you'e looking for: Principles of effective SNP filtering for molecular ecologists. Molecular Ecology, 27(16), 3193-3206. doi: /10.1111/mec.14792

O'Reilly, P. T., \& Kozfkay, C. C. (2014). Use of microsatellite data and pedigree information in the genetic management of two long-term salmon conservation programs. Reviews in Fish Biology and Fisheries, 24(3), 819-848. doi: /10.1007/s11160-014-9347-9

Overbeek, A., Galla, S., Brown, L., Cleland, S., Thyne, C., Maloney, R., \& Steeves, T. (2020). Pedigree validation using genetic markers in an intensively-managed taonga species, the critically endangered kaki (Himantopus novaezelandiae). Notornis, 67(4), 709-716.

Pelgas, B., Bousquet, J., Meirmans, P. G., Ritland, K., \& Isabel, N. (2011). QTL mapping in white spruce: gene maps and genomic regions underlying adaptive traits across pedigrees, years and environments. $B M C$ Genomics, 12(1), 1-23. doi: /10.1186/1471-2164-12-145

Polfus, J. L., Manseau, M., Simmons, D. , Neyelle, M., Bayha, W. , Andrew, F., Andrew, L., Klutsch, C. F. C. , Rice, K., \& Wilson, P. (2016). Leghagots'enete (learning together): the importance of indigenous perspectives in the identification of biological variation. Ecology and Society, 21(2):18. doi: 10.5751/ES08284-210218

Putnam, A. S., \& Ivy, J. A. (2014). Kinship-based management strategies for captive breeding programs when pedigrees are unknown or uncertain. Journal of Heredity, 105(3), 303-311.

Rabier, R., Robert, A., Lacroix, F., \& Lesobre, L. (2020). Genetic assessment of a conservation breeding program of the houbara bustard (Chlamydotis undulata undulata) in Morocco, based on pedigree and molecular analyses. Zoo Biology, 39(6), 422-435. doi: 10.1002/zoo.21569

Ralls, K., Ballou, J. D., Rideout, B. A., \& Frankham, R. (2000). Genetic management of chondrodystrophy in California condors. Animal Conservation, 3(2), 145-153. doi: /10.1111/j.1469-1795.2000.tb00239.x

Ralls, K., Sunnucks, P., Lacy, R. C., \& Frankham, R. (2020). Genetic rescue: A critique of the evidence supports maximizing genetic diversity rather than minimizing the introduction of putatively harmful genetic variation. Biological Conservation, 251, 108784. doi: /10.1016/j.biocon.2020.108784

Reid, J. M., Nietlisbach, P., Wolak, M. E., Keller, L. F., \& Arcese, P. (2019). Individuals' expected genetic contributions to future generations, reproductive value, and short-term metrics of fitness in free-living song sparrows (Melospiza melodia). Evolution Letters, 3(3), 271-285.

Rhie, A., McCarthy, S. A., Fedrigo, O., Damas, J., Formenti, G., Koren, S., .. \& Jarvis, E. D. (2021). Towards complete and error-free genome assemblies of all vertebrate species. Nature, 592(7856), 737-746. doi: /10.1038/s41586-021-03451-0

Richardson, B. A., \& Chaney, L. (2018). Climate-based seed transfer of a widespread shrub: population shifts, restoration strategies, and the trailing edge. Ecological Applications, 28(8), 2165-2174. doi: /10.1002/eap.1804

Roberts, M. (2013). Ways of seeing: whakapapa. SITES: A Journal of Social Anthropology and Cultural Studies, 10(1): 93-120. doi: 10.11157/sites-vol10iss1id236

Robinson, J. A., Bowie, R. C., Dudchenko, O., Aiden, E. L., Hendrickson, S. L., Steiner, C. C., .. \& \& Wall, J. D. (2021). Genome-wide diversity in the California condor tracks its prehistoric abundance and decline. Current Biology. doi: /10.1016/j.cub.2021.04.035

Romanov, M. N., Tuttle, E. M., Houck, M. L., Modi, W. S., Chemnick, L. G., Korody, M. L., .. \& Ryder, O. A. (2009). The value of avian genomics to the conservation of wildlife. BMC Genomics, 10, S10. doi: /10.1186/1471-2164-10-S2-S10 
Roshyara, N. R., Kirsten, H., Horn, K., Ahnert, P., \& Scholz, M. (2014). Impact of pre-imputation SNPfiltering on genotype imputation results. BMC genetics, 15(1), 1-11.

Sargolzaei, M., Chesnais, J. P., \& Schenkel, F. S. (2014). A new approach for efficient genotype imputation using information from relatives. BMC Genomics, 15(1), 1-12. doi: /10.1186/1471-2164-15-478

Sewell, M. M., Sherman, B. K., \& Neale, D. B. (1999). A consensus map for loblolly pine (Pinus taeda L.). I. Construction and integration of individual linkage maps from two outbred three-generation pedigrees. Genetics, 151(1), 321-330.

Shafer, A. B., Wolf, J. B., Alves, P. C., Bergström, L., Bruford, M. W., Brännström, I., .. \& Zieliński, P. (2015). Genomics and the challenging translation into conservation practice. Trends in Ecology $\&$ Evolution, 30(2), 78-87. doi: /10.1016/j.tree.2014.11.009

Shier, D. M. (2006). Effect of family support on the success of translocated black-tailed prairie dogs. Conservation Biology, 20(6), 1780-1790. doi: /10.1111/j.1523-1739.2006.00512.x

Slate, J. (2005). Quantitative trait locus mapping in natural populations: progress, caveats and future directions. Molecular Ecology, 14 (2), 363-379. doi: /10.1111/j.1365-294X.2004.02378.x

Slate, J., Gratten, J., Beraldi, D., Stapley, J., Hale, M., \& Pemberton, J. M. (2009). Gene mapping in the wild with SNPs: guidelines and future directions. Genetica, 136(1), 97-107. doi: 10.1007/s10709-008-9317-z

Smith, J. S. C., Duvick, D. N., Smith, O. S., Cooper, M., \& Feng, L. (2004). Changes in pedigree backgrounds of Pioneer brand maize hybrids widely grown from 1930 to 1999. Crop Science, 44(6), 1935-1946. doi:/10.2135/cropsci2004.1935

Species360. 2021. Zoological Information Management System (ZIMS). zims.Species360.org.

Speed, D., \& Balding, D. J. (2015). Relatedness in the post-genomic era: is it still useful?. Nature Reviews Genetics, 16(1), 33-44. doi: /10.1038/nrg3821

Stapley, J., Feulner, P. G., Johnston, S. E., Santure, A. W., \& Smadja, C. M. (2017). Variation in recombination frequency and distribution across eukaryotes: patterns and processes. Philosophical Transactions of the Royal Society B: Biological Sciences, 372(1736), 20160455. doi: /10.1098/rstb.2016.0455

Tau, T. (2001). In defence of whakapapa as oral history: A case study. Te Karaka, 17, 8-9.

Taylor, H. R. (2015). The use and abuse of genetic marker-based estimates of relatedness and inbreeding. Ecology and Evolution, 5(15), 3140-3150.

Te Rito, J. S. (2007). Whakapapa: A framework for understanding identity. MAI Review LW, $1(3), 10$.

Tettelin, H., Masignani, V., Cieslewicz, M. J., Donati, C., Medini, D., Ward, N. L., .. Fraser, C. M. (2005). Genome analysis of multiple pathogenic isolates of Streptococcus agalactiae: Implications for the microbial "pan-genome." Proceedings of the National Academy of Sciences, 102(39), 13950-13955. doi: /10.1073/pnas.0506758102

Tomaszkiewicz, M., Medvedev, P., \& Makova, K. D. (2017). Y and W chromosome assemblies: approaches and discoveries. Trends in Genetics, 33(4), 266-282. doi: /10.1016/j.tig.2017.01.008

Ullah, E., Mall, R., Abbas, M. M., Kunji, K., Nato, A. Q., Bensmail, H., . . \& Saad, M. (2019). Comparison and assessment of family-and population-based genotype imputation methods in large pedigrees. Genome Research, 29(1), 125-134. doi: /10.1101/gr.236315.118

vonHoldt, B. M., DeCandia, A. L., Heppenheimer, E., Janowitz-Koch, I., Shi, R., Zhou, H., . . \& Sinsheimer, J. S. (2020). Heritability of interpack aggression in a wild pedigreed population of North American grey wolves. Molecular Ecology, 29(10), 1764-1775. doi: /10.1111/mec.15349 
Westbrook, J. W., Zhang, Q., Mandal, M. K., Jenkins, E. V., Barth, L. E., Jenkins, J. W., .. \& \& Holliday, J. A. (2020). Optimizing genomic selection for blight resistance in American chestnut backcross populations: A trade-off with American chestnut ancestry implies resistance is polygenic. Evolutionary Applications, 13(1), 31-47. doi: /10.1111/eva.12886

Wildt, D., Miller, P., Koepfli, K. P., Pukazhenthi, B., Palfrey, K., Livingston, G., . . \& Snodgrass, K. (2019). Breeding centers, private ranches, and genomics for creating sustainable wildlife populations. BioScience, 69(11), 928-943. doi: /10.1093/biosci/biz091

Willoughby, J. R., Fernandez, N. B., Lamb, M. C., Ivy, J. A., Lacy, R. C., \& DeWoody, J. A. (2015). The impacts of inbreeding, drift and selection on genetic diversity in captive breeding populations. Molecular Ecology, 24(1), 98-110. https://doi.org/10.1111/mec.13020

Wilson, A. J., Reale, D., Clements, M. N., Morrissey, M. M., Postma, E., Walling, C. A., .. \& Nussey, D. H. (2010). An ecologist's guide to the animal model. Journal of Animal Ecology, 79(1), 13-26. doi: /10.1111/j.1365-2656.2009.01639.x

Wold, J. R., Galla, S. J., Santure, A., Eccles, D., Hogg, C. J., Le Lec, M., Koepfli, K-P., Guhlin, J., Steeves, T. (2021). Expanding the conservation genomics toolbox: incorporating structural variants to enhance genomic studies for species of conservation concern. Molecular Ecology, doi:10.1111/mec.

Wood, J., Ballou, J. D., Callicrate, T., Fant, J. B., Griffith, M. P., Kramer, A. T., . . \& Havens, K. (2020). Applying the zoo model to conservation of threatened exceptional plant species. Conservation Biology, 34(6), 1416-1425. doi: /10.1111/cobi.13503

Woodruff, D.S. (2001). Populations, species, and conservation genetics. Encyclopedia of biodiversity, p.811.

Wright, S. (1922). Coefficients of inbreeding and relationship. The American Naturalist, 56 (645), 330-338.

Wright, B. R., Hogg, C. J., McLennan, E. A., Belov, K., \& Grueber, C. E. (2021). Assessing evolutionary processes over time in a conservation breeding program: a combined approach using molecular data, simulations and pedigree analysis. Biodiversity and Conservation, 30(4), 1011-1029. doi: /10.1007/s10531-021-02128-4.

Yang, J., Guo, B., Shikano, T., Liu, X., \& Merilä, J. (2016). Quantitative trait locus analysis of body shape divergence in nine-spined sticklebacks based on high-density SNP-panel. Scientific Reports, 6(1), 1-16. doi: $10.1038 /$ srep26632

Yoder, A. D., Poelstra, J. W., Tiley, G. P., \& Williams, R. C. (2018). Neutral theory is the foundation of conservation genetics. Molecular Biology and Evolution, 35(6), 1322-1326. doi: /10.1093/molbev/msy076.

Yoko, Z. G., Volk, K. L., Dochtermann, N. A., \& Hamilton, J. A. (2020). The importance of quantitative trait differentiation in restoration: landscape heterogeneity and functional traits inform seed transfer guidelines. AoB Plants, 12(2), 1-13. doi: /10.1093/aobpla/plaa009

Young, A. I., Benonisdottir, S., Przeworski, M., \& Kong, A. (2019). Deconstructing the sources of genotypephenotype associations in humans. Science, 365(6460), 1396-1400.

Young, M. J., Dutoit, L., Robertson, F., van Heezik, Y., Seddon, P. J., \& Robertson, B. C. (2020). Species in the faeces: DNA metabarcoding as a method to determine the diet of the endangered yellow-eyed penguin. Wildlife Research, 47(6), 509-522. doi:/10.1071/WR19246

Yusefi, G. H., Khalatbari, L., Jowers, M. J., Fahimi, H., Costa, V., Björklund, M., \& Beja-Pereira, A. (2020). Phylogenetic analysis of marginal Asiatic black bears reveals a recent Iranian-Himalayan divergence and has implications for taxonomy and conservation. Mammalian Biology, 100(4), 419-427. doi:10.1007/s42991-02000044-8.

Zhang, Y., Luan, P., Ren, G., Hu, G., \& Yin, J. (2020). Estimating the inbreeding level and genetic relatedness in an isolated population of critically endangered Sichuan taimen (Hucho bleekeri) using genome-wide SNP markers. Ecology and Evolution, 10(3), 1390-1400. doi:/10.1002/ece3.5994 
Zhou, H., Blangero, J., Dyer, T. D., Chan, K. H. K., Lange, K., \& Sobel, E. M. (2017). Fast genome-wide QTL association mapping on pedigree and population data. Genetic Epidemiology, 41(3), 174-186. doi: /10.1002/gepi.21988.

\section{Author Contributions}

The conception of this piece was led by SJG and TES, with support from all authors. Writing and illustrations were led by SJG with contributions from all authors. Box 1 was led by LB, DE, and AR, with support from SJG. Box 2 was written by SJG, YCL, and TES.

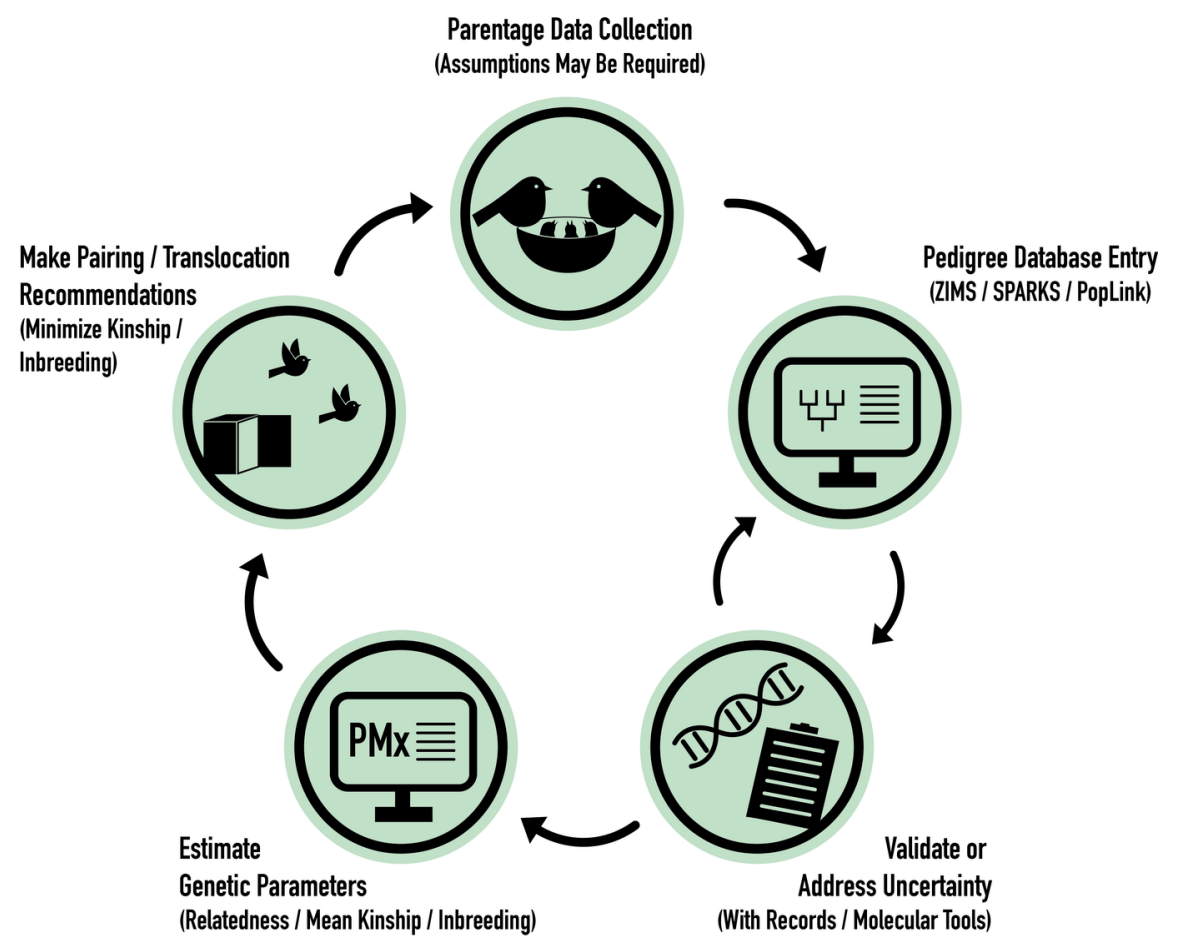

Figure 1: Schematic detailing one use of pedigrees in conservation breeding programs to maximize genomewide diversity. Parentage data is collected in ex situ or in situ environments, entered into databases using readily available software, validated when necessary using records and molecular tools, used to estimate genetic parameters, and inform conservation decisions
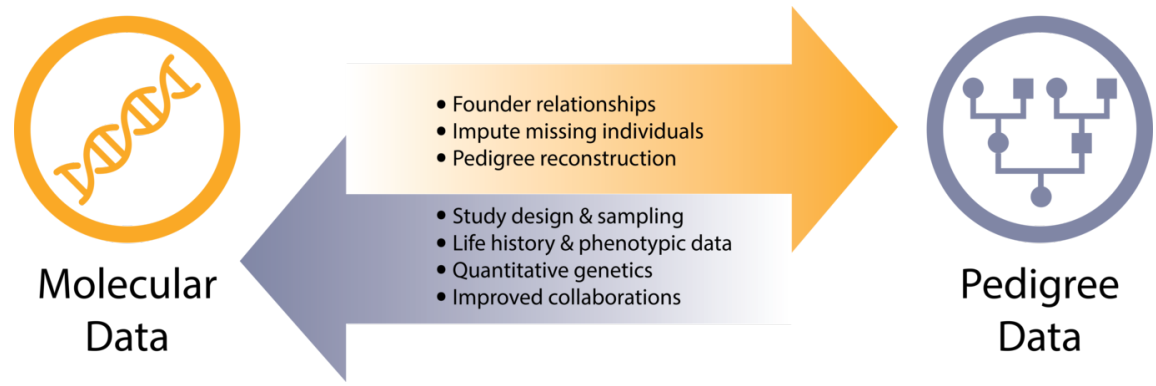

Figure 2: Diagram illustrating the mutual benefits between molecular (e.g., genetic/genomic) and pedigree data. 
Box 1: Perspectives from conservation practitioners on the benefits of pedigree use in species management. Viewpoints provided by Liz Brown (LB), Daryl Eason (DE), and Anne Richardson (AR).

We ( $\mathrm{LB}, \mathrm{DE}$, and $\mathrm{AR}$ ) are conservation practitioners in Aotearoa New Zealand working with three critically-endangered endemic bird species with pedigree data: kākāpō (Strigops habroptilus; Box1A), kākāriki karaka (Cyanoramphus malherbi; Box1B), and kakī (Himantopus novaezelandiae; Box1C). Over the past 5 years, we have collaborated with conservation researchers to integrate pedigrees from long-term records into digital studbook databases (kākāpō and kakī), validate pedigrees with genetic and genomic data (all), and inform genetic and genomic studies with our research collaborators using pedigree data (all).

Collecting, validating, and managing pedigree data is time intensive. For example, building a pedigree for kaki from scratch, and validating it using genetic and genomic data, has taken well over 500 hours to accomplish (Galla, 2020). However, in our collective experience, creating pedigree resources for these species has been worth the effort. Pedigrees have allowed us to make informed translocation recommendations in kākāpō, pairing recommendations in kakī and kākāriki karaka, and understand the founder representation and demographics in all three species. Because kakī is semi-wild and kākāpō is a wild lek breeder, genetic and genomic data has been helpful in validating the parentage we have assigned for each offspring. Given our relationships with conservation researchers at universities, this data has contributed towards genomic studies for each of these species, including the efforts of Kākāpō 125+, a project to sequence the genomes of all living kākāpō .

The act of collaborating with conservation researchers on building pedigrees has required substantial communication between researchers and practitioners. The time and energy required to communicate (e.g., emails, phone calls, face-to-face meetings, workshops) has not only strengthened our pedigree tools and our confidence using them, but importantly has also strengthened our relationships. The pedigree acts as a common ground between conservation genetic research and practice, and has contributed towards trust that allows genetic research to inform management efforts for these critically endangered species. These trusted relationships have built a bridge for us to learn about aligned conservation projects in Aotearoa New Zealand and abroad, and incorporate new approaches for pedigree and species management in our own programmes.

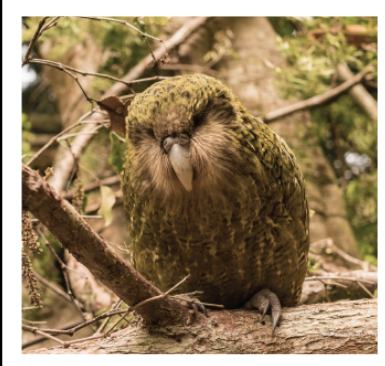

Box1A. Kākāpō

Strigops habroptilus

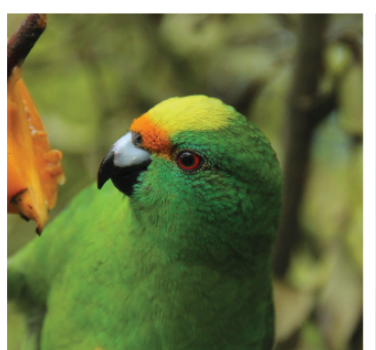

Box1B. Kākāriki karaka Cyanoramphus malherbi

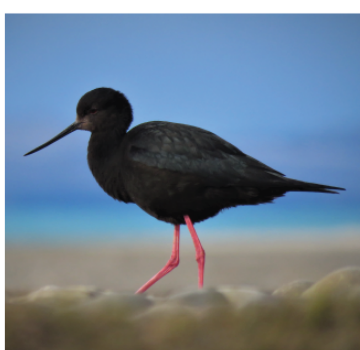

Box1C. Kākī Himantopus novaezelandiae

Box 2. Pedigrees for culturally significant species help grow relationships with Indigenous Peoples and Local Communities. Viewpoints provided by Yvette Couch-Lewis (YCL), Stephanie J. Galla (SJG) and Tammy E. Steeves (TES). 
We are conservationists representing mana whenua (those with local tribal or sub-tribal authority, YCL) and genetic researchers (SJG, TES) who work in partnership to enhance the recovery of threatened species treasured by Mãori (the Indigenous Peoples of Aotearoa New Zealand).

For Māori, whakapapa is a genealogical framework that describes the origins and relationships of all things, linking plants, animals, and people with the environment including the mountains, rivers, and winds, across time and space (Tau, 2001; Roberts, 2013). Ultimately, it is whakapapa that connects individuals to each other, to their ancestors, and to the land (Tau, 2001; Te Rito, 2007). Given this worldview, it is no wonder that relationships between researchers and mana whenua are enriched by pedigrees, which provide a visualization of whakapapa.

YCL is kaitiaki (guardian) for kākāriki karaka, or orange-fronted parakeet, on behalf of Ngäi Tahu, a large tribe on the South Island of Aotearoa New

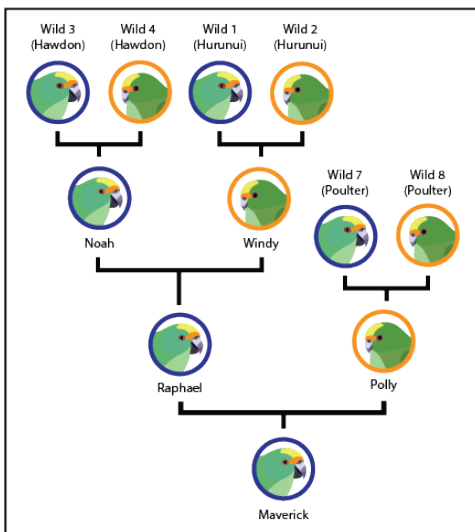

Box 2A. Partial pedigree hand-drawn by SJG and TES showing the whakapapa of Maverick, the individual selected by YCL for the kākāriki karaka reference genome. Blue circles denote males; orange circles geno. Blue circles denote males; orange circles three remnant kākāriki karaka populations on th three remnant kākāriki karaka populations on the mainland of Aotearoa New Zealand in the Hawdon,
Hurunui and Poulter Valleys of North Canterbury.

Zealand. When deciding which individual to

choose for the kākāriki karaka reference genome, we (SJG, TES) provided a pedigree showing the whakapapa of all individuals available for sampling. Using this resource, YCL chose Maverick, a captive male bird. From the pedigree, she learned that his ancestors included individuals from the last three remnant populations on the mainland (Box 2A), and that he was a good father (he had many offspring; data not shown). Simply put, Maverick provided a link between the past-and the future-of kākāriki karaka with the land, and his genome remains an invaluable resource for the conservation genomic management of this critically-endangered Aotearoa New Zealand endemic bird (e.g., Galla et al., 2020).

Beyond kākāriki karaka, based on our collective experience working with other threatened taonga (treasured) species in Aotearoa New Zealand, we are confident pedigrees will continue to help grow our relationships with mana whenua-as well as local communities-leading to improved conservation outcomes. We encourage those interested in building trusted relationships with Indigenous Peoples and Local Communities to seek guidance relevant to their local context and to engage in the extensive scholarship already available (e.g., Polfus et al., 2016; Collier-Robinson et al., 2019; Chambers et al., 2021). 